\title{
Adipocyte related peptides - galanin and resistin in endometrioid type endometrium cancer
}

\author{
Sumeyra Nergiz Avcioğlu(D, Hasan Yüksel(1) \\ Adnan Menderes University Faculty of Medicine Department of Obstetrics and Gynecology Aydın, Turkey
}

\begin{abstract}
Objectives: The aim of (this) study was to investigate concentrations of galanin and resistin in patients with endometrioid type endometrium cancer.

Material and methods: A total of 85 patients (52 Endometrioid type Endometrium Cancer patients and 33 healthy controls) were included in the study. Serum galanin and resistin levels were measured by an enzyme-linked immunosorbent assay (ELISA).

Results: It was found that the sensitivity and specificity of galanin at the cut off level of $0,37 \mathrm{ng} / \mathrm{mL}$, was $82.96 \%$ and $68.78 \%$ respectively (AUC $=0.795, \mathrm{Cl}: 0.691-0.898, \mathrm{p}<0.001$ ). Sensitivity and specificity of resistin at the $0.27 \mathrm{ng} / \mathrm{mL}$ cut off level, was found to be $82.95 \%$ and $59.12 \%$ respectively ( $\mathrm{AUC}=0.705, \mathrm{Cl}: 0.588-0.822, \mathrm{p}<0.001$ ) for prediction of endometrioid type endometrium cancer diagnosis. Bivariate logistic regression analysis showed that, increased galanin concentration, greater than $0.37 \mathrm{ng} / \mathrm{mL}$, increased the risk of having endometrioid type endometrium cancer 10.2 times (95\% Cl: $3.425-30.881, \mathrm{p}<0.001$ ) and resistin concentration $>0.27 \mathrm{ng} / \mathrm{mL}$, increased the risk of having endometrioid type endometrium cancer 5.6 fold ( $95 \% \mathrm{Cl}: 1.939-16.282, \mathrm{p}=0.001$ ). On the other hand, according to adjusted Odds Ratio results of the multiple logistic regression analysis, effect of interaction between galanin and resistin on having endometrioid type endometrium cancer was statistically significant. Increased galanin concentration $>0.37 \mathrm{ng} / \mathrm{mL}$ with increased resistin concentration $>0.27 \mathrm{ng} / \mathrm{mL}$ had adjusted Odds Ratio $=27.182$ times greater risk of having endometrioid type endometrium cancer ( $95 \% \mathrm{Cl}: 6.653$ to $111.109, \mathrm{p}<0.001)$.
\end{abstract}

Conclusions: Increased galanin and resistin levels, either separately or together with, seemed to increase the risk of endometrioid type endometrium cancer other than different risk factors.

Key words: galanin; resistin; adipose tissue; endometrioid type endometrium cancer

Ginekologia Polska 2022; 93, 12: 941-947

\section{INTRODUCTION}

The most common gynecological malignancy worldwide is cervical cancer, while endometrial cancer remains leading gynecological neoplasm in developed countries [1]. Obesity has been the most important risk factor blamed for EC for many years. In obesity, aromatization of androstenedione to estrone was increased in adipose tissue and cause increase in estrogen levels in circulation. From clinical and epidemiological studies, in EC classification, there two groups; type I and type II tumors. Two types of tumor have different patterns of molecular changes underlying pathogenesis. In EC, $80 \%$ of the cancers were Type I tumors. This type demonstrates low-grade endometrioid histology. They frequently develop on the basis of premalignant hyperplastic lesions. Unlikely, Type Il cancers are mostly of non-endometrioid serous or clear-cell histology. They are not related to hyperestrogenism and mostly seen in older women atropic endometrium [2]. So, the association is not totally accounted for by aromatization. Genetic mutations (such as in phosphatase tensin homolog, PTEN) were investigated in the pathogenesis of EC. In addition, adipocytes derived factors have also blamed for the regulation of cancer cell growth [3]. Insulin resistance may also help to explain the missing link between obesity and EC.

There have been researches claiming adipocytes related peptides in pathogenesis of EC. It is known that increased levels of these adipokines can cause initiation, progression, and metastasis of tumors [4]. Galanin and resistin are two of them. Galanin is a 30-amino acid peptide. It has three specific receptors galanin receptor 1-3 (GALR1-3).

\footnotetext{
Corresponding author:

Sumeyra Nergiz Avcioğlu

Adnan Menderes University Faculty of Medicine Department of Obstetrics and Gynecology Aydın, Turkey

e-mail: sumeyranergiz80@gmail.com
} 
Mainly, galanin and its receptors are expressed in the central and peripheral nervous systems and function in neurotransmission. This neuroendocrine peptide also stimulates food intake and regulates energy metabolism [5]. Recently, galanin has been also shown to regulate cell proliferation and survival in many tumors [6]. For example there have been many genetic researches about galanin in head and neck tumors, gastrointestinal tumors like colon and pancreas, and intracranial tumors like hypophysis adenoma [7]. However there has been only one research about GALR1 methylation in vaginal swabs of patients with EC [8].

Resistin is another adipokine having 114 amino acids. It is a member of the resistin-like family of proteins. It was shown that resistin acts as a link between obesity, insulin resistance and diabetes mellitus (DM) in animal studies. Besides a positive correlation was determined between resistin levels and pro-inflammatory factors in many diseases like respiratory tract inflammation, renal disease, atherosclerosis [9]. Because of its relationship between inflammation and comorbidities of cardiovascular disease, resistin has been also blamed as a potential risk factor of metabolic syndrome. Higher serum resistin level was determined in adults with metabolic syndrome compared to healthy people [10]. There have been researches about resistin in various cancer types like pancreas, breast, gastric, colorectal and esophageal cancers [11].

The aim of the current study was to investigate concentration of two adipocyte related peptides: galanin and resistin in patients with endometrioid type endometrium cancer (EEC).

\section{MATERIAL AND METHODS}

This prospective cohort study was conducted at Adnan Menderes University Hospital. The Ethics Committee of Adnan Menderes University approved the study. Informed consent was taken from all of the patients. Fifty-two histologically confirmed EEC women were included in the study population. Prior to surgery, none of them had undergone radiotherapy or chemotherapy. In control group, there were age and BMI matched patients, presenting with abnormal uterine bleeding and histologically confirmed benign conditions. Patients with any other cancer diagnosis were excluded.

Demographic information (obstetric history, age, hypertension, DM, and family history of DM) was included. Formula of weight $(\mathrm{kg}) /$ height $^{2}\left(\mathrm{~m}^{2}\right)$ was used for Body Mass Index (BMI) calculation. Blood analysis of each patient was performed in morning after at least 6 hrs fasting, before surgery. Fasting insulin, fasting blood glucose, High Density Lipoprotein (HDL), Low Density Lipoprotein (LDL), total cholesterol (TC), triglyceride (TG), levels were measured. Insulin resistance was determined by the homeostasis model assessment -resistance index (HOMA-IR) [11]. Matthews'Formula [13] as: [fasting plasma insulin $\mu \mathrm{lU} / \mathrm{ml} \mathrm{x}$ fasting plasma glucose $(\mathrm{mg} / \mathrm{dl})]$ / 405 was used for HOMA-IR calculation. Enzyme immunoassay (ARCHITECT CA 125 II Reagent Kit and ARCHITECT CA 19-9 Reagent Kit, ARCHITECT CA 15-3 II Reagent Kit- Abbott Laboratories, USA-North Chicago-Illinois) was used for measurement of plasma levels of CA15-3, CA-125, CA19-9.

Patients in study and control groups gave fasting venous blood in morning to determine serum levels of galanin, resistin and other biochemical parameters. Within $30 \mathrm{~min}$ of collection, the blood samples were immediately centrifuged for $15 \mathrm{~min}$ at $1000 \times \mathrm{g}$ at $4^{\circ} \mathrm{C}$ for measurement of galanin and resistin. Serum was stored at $-80^{\circ} \mathrm{C}$ until measurement. ELISA assays [Human Galanin ELISA kit and Human Resistin ELISA kit; Sunred Biological Technology, Shanghai, China] were used to determine levels of galanin and resistin

In hysterectomy specimens, pathologic examination was performed. A modified World Health Organization (WHO) classification system was used to determine the histological type and grade of the primary tumors. Besides endometrial type endometrium cancer (ECC) staging was performed based on a modified 2009 International Federation of Gynaecology and Obstetrics (FIGO) staging system [14].

\section{Statistical analysis}

Statistical Package for the Social Sciences (SPSS) 18 statistical analysis program was used. The Kolmogorov-Smirnov test was used to assess the normality of numeric variables. For the numeric variables that were normally distributed, comparison between two groups was made by independent sample t test and descriptive statistics are presented as mean \pm standard deviation. For the numeric variables that were not normally distributed, comparison between two groups was made by Mann-Whitney $U$ test and descriptive statistics are presented as median (25-75 percentiles). A chi-square test was used to analyze the categorical data, and descriptive statistics are presented as frequency (\%). Pearson correlation was used for quantitative data and Spearman correlation was used for qualitative data. Receiver operator characteristic (ROC) curve analysis and calculation of the area under the curve (AUC) were performed. We used the logistic regression analysis in order to determine effects of risk factors for illness of EEC. The $p$ values $<0.05$ were considered statistically significant.

\section{RESULTS}

In the present study, a total of 52 women with EEC and 33 controls were included. Demographic, clinical, and biochemical data of women with and without EEC were presented in Table 1. Mean age of patients in control group was $54.57 \pm 10.21$ and $58.52 \pm 7.51$ in patients with EEC. 


\begin{tabular}{|c|c|c|c|}
\hline & Control Group ( $n=33$ ) & EEC Group $(n=52)$ & $\mathbf{p}$ \\
\hline Age [years] & $54.57 \pm 10.21$ & $58.52 \pm 7.51$ & 0.091 \\
\hline $\mathrm{BMI}\left[\mathrm{kg} / \mathrm{m}^{2}\right]$ & $31.12 \pm 5.91$ & $32.89 \pm 5.03$ & 0.192 \\
\hline $\mathrm{DM}[\mathrm{n}, \%]$ & $2(7.1 \%)$ & $20(38.4 \%)$ & 0.005 \\
\hline Familial DM[n,\%] & $10(30.3 \%)$ & $24(46.15 \%)$ & 0.026 \\
\hline $\mathrm{HT}[\mathrm{n}, \%]$ & $8(24.2 \%)$ & $25(48.07 \%)$ & 0.043 \\
\hline $\mathrm{FBG}[\mathrm{mg} / \mathrm{dL}]$ & $102.25 \pm 23.74$ & $127.38 \pm 44.83$ & 0.168 \\
\hline $\mathrm{FI}[\mu \mathrm{IU} / \mathrm{mL}]$ & $8.42(6.20-12.64)$ & $13.48(8.72-22.43)$ & 0.029 \\
\hline HOMA-IR & $2.29(1.38-3.18)$ & $3.86(2.04-7.52)$ & 0.005 \\
\hline $\mathrm{TC}[\mathrm{mg} / \mathrm{dL}]$ & $173.58 \pm 36.28)$ & $212.85 \pm 47.54$ & 0.018 \\
\hline $\mathrm{HDL}[\mathrm{mg} / \mathrm{dL}]$ & $39.55(33-52.50)$ & $47(36-57)$ & 0.328 \\
\hline $\mathrm{LDL}[\mathrm{mg} / \mathrm{dL}]$ & $114.72 \pm 31.22$ & $128.78 \pm 31.08$ & 0.064 \\
\hline $\mathrm{TG}[\mathrm{mg} / \mathrm{dL}]$ & $108.48(86.55-132)$ & $134(98-197)$ & 0.051 \\
\hline CA125 [U/mL] & $12.32(9.80-16.47)$ & $16.2(8.30-27.18)$ & 0.375 \\
\hline CA19-9[U/mL] & $7.16(3.18-19.31)$ & $14.61(6-35.48)$ & 0.046 \\
\hline CA15-3[U/mL] & $15.96 \pm 8.25$ & $17.45 \pm 8.34$ & 0.810 \\
\hline Galanin [ng/mL] & $0.24(0.11-0.49)$ & $0.61(0.44-0.82)$ & $<0.001$ \\
\hline Resistin[ng/mL] & $0.27(0.07-0.49)$ & $0.43(0.28-0.65)$ & 0.004 \\
\hline
\end{tabular}

ECC — Endometrial type endometrium cancer; BMI — body mass index; DM — diabetes mellitus; $\mathrm{HT}$ - hypertension; FBG — fasting blood glucose; FI — fasting insulin; HOMA-IR - Homeostasis Model Assessment-Insulin resistance; TC — total cholesterol; HDL — high density lipoprotein; LDL — low density lipoprotein; TG — triglycerides; $p$; difference between women with ECC and controls; $p$ value less than 0.05 was considered statistically significant

All patients were at postmenopausal period defined as amenorrhea for one year and blood follicle stimulating hormone (FSH) level greater than $40 \mathrm{ng} / \mathrm{ml}$. Serum galanin and resistin levels were found higher in patients with EEC compared with control group ( $p<0.01$ ).

Correlation analysis between demographic, clinical and histopathologic characteristics with serum galanin and resistin levels of all patients was performed in study. Serum galanin levels were positively correlated with BMI ( $r=0.434$, $p<0.01)$, fasting insulin $(r=0.401, p<0.01)$ levels and HOMA-IR $(r=0.362, p=0.01)$. Resistin concentrations were also positively correlated with fasting insulin $(r=0.272$, $\mathrm{p}=0.02)$ and HOMA-IR ( $r=0.262, \mathrm{p}=0.023)$ but not correlated with BMI ( $p>0.05$ ). (Tab. 2) Among all participants, in patients with age $<60 \mathrm{y}$, only galanin was correlated with BMI $(r=0.533, p<0.01)$, fasting insulin $(r=0.439, p=0.003)$ and HOMA-IR $(r=0.392, p=0.006)$.In patients with age $\geq 60$, only resistin was positively correlated with fasting insulin ( $r=0.433, p=0.21)$ and HOMA-IR $(r=0.474, p=0.011)$ but not correlated with BMI $(p>0.05)$. In patients older than 60 , galanin concentration was not correlated with BMI, fasting insulin and HOMA-IR ( $p>0.05)$.

In EEC group, 52 patients were included. In that group, only galanin levels were positively correlated with BMI $(r=0.492, p<0.001)$. Galanin concentrations were higher in patients having $\mathrm{BMI} \geq 30 \mathrm{~kg} / \mathrm{m}^{2}$ than patients with $\mathrm{BMl}<30 \mathrm{~kg} / \mathrm{m}^{2}(\mathrm{p}<0.016)$. However resistin concentrations

\begin{tabular}{|c|c|c|c|c|}
\hline \multirow[b]{2}{*}{ Variables } & \multicolumn{2}{|c|}{ Galanin (ng/mL) } & \multicolumn{2}{|c|}{ Resistin (ng/mL) } \\
\hline & $r$ & p & $\mathbf{r}$ & p \\
\hline Age [years] & 0.052 & 0.653 & -0.026 & 0.816 \\
\hline BMI $\left[\mathrm{kg} / \mathrm{m}^{2}\right]$ & 0.434 & $<0.01$ & 0.096 & 0.412 \\
\hline FBG [mg/dL] & 0.74 & 0.514 & 0.069 & 0.571 \\
\hline $\mathrm{FI}[\mu \mathrm{IU} / \mathrm{mL}]$ & 0.401 & $<0.01$ & 0.272 & 0.02 \\
\hline HOMA-IR & 0.362 & 0.001 & 0.262 & 0.023 \\
\hline $\mathrm{HDL}[\mathrm{mg} / \mathrm{dL}]$ & -0.022 & 0.843 & -0.127 & 0.284 \\
\hline LDL [mg/dL] & 0.164 & 0.171 & 0.105 & 0.390 \\
\hline $\mathrm{TG}[\mathrm{mg} / \mathrm{dL}]$ & 0.141 & 0.224 & 0.265 & 0.022 \\
\hline $\mathrm{TC}[\mathrm{mg} / \mathrm{dL}]$ & 0.165 & 0.155 & 0.137 & 0.235 \\
\hline $\mathrm{CA} 125[\mathrm{U} / \mathrm{mL}]$ & -0.056 & 0.624 & 0.064 & 0.597 \\
\hline CA15-3 [U/mL] & 0.010 & 0.941 & -0.060 & 0.620 \\
\hline CA19-9 [U/mL] & 0.026 & 0.840 & 0.107 & 0.376 \\
\hline
\end{tabular}

$\mathrm{BMI}$ - body mass index; FPG — fasting blood glucose; $\mathrm{FI}$ - fasting insulin; HOMA-IR - Homeostasis Model Assessment-Insulin resistance; TC — total cholesterol; $\mathrm{HDL}$ — high density lipoprotein; LDL — low density lipoprotein; TG — triglycerides; $r$ —correlation coefficient; statistical significance $p<0.05$

were not different between obese and nonobese patients in EEC group. Galanin and resistin concentrations were not different in patients with age $<60$ and $\geq 60$ years ( $p>0.05$ ).

According to separate correlation analysis for ECC group and control group, only in ECC group galanin was correlated 


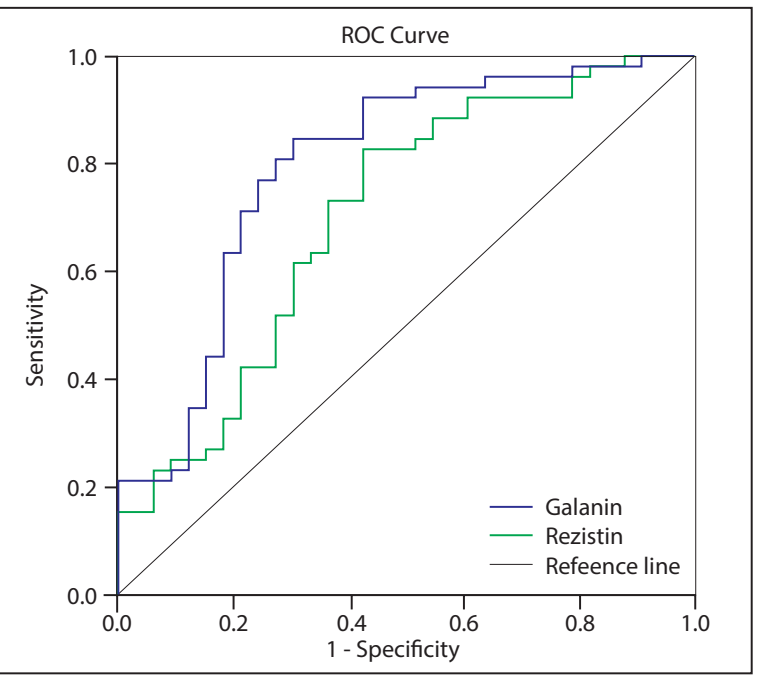

Figure 1. Receiver operating characteristic curves of the galanin and resistin in all participants; $\mathrm{ROC}$ - receiver operator characteristic

with BMI $(r=0.493, p=0.01)$,age $(r=-0.330, p=0.024)$, HOMA-IR ( $r=0.203, p=0.01)$, fasting insulin $(r=0.280$, $p=0.05)$ and resistin was correlated with HOMA-IR $(r=0.306$, $p=0.037)$ and fasting insulin $(r=0.312, p=0.033)$ but not correlated with BMI. These correlations were not determined in control group.

In our study, 31 patients (59.6\%) were FIGO Stage $1 \mathrm{~A}$, $11(21.3 \%)$ patients were FIGO Stage 1B, four patients $(7.6 \%)$ were FIGO Stage 2, three patients (6.4\%) were FIGO Stage $3 \mathrm{~A}$, three patients (6.4\%) were FIGO Stage $3 \mathrm{~B}$ according to FIGO histopathologic staging system. Besides, 19 (36.5\%) patients had $>1 / 2$ myometrial invasion and 33 (63.4\%) patients had EC with $<1 / 2$ myometrial invasion. Only four patients (7.6\%) had lymph node metastasis. Median tumor diameter was $3.11 \pm 1.36(0.4-6.0) \mathrm{cm}$. In EC group, there was no statistical difference in serum galanin and resistin levels between FIGO stage 3-4 EC and FIGO stage1-2 EC patients, patients with $>1 / 2$ myometrial invasion and $<1 / 2$ myometrial invasion $(p>0.05)$. There was no correlation between serum resistin and galanin levels and grade of disease $(p>0.05)$. Only serum galanin concentrations were determined lower in patients with lymph node metastasis $(p=0.026)$.

It was found that the sensitivity of galanin $>0.3716 \mathrm{ng} / \mathrm{mL}$ was $82.96 \%$ with a specificity of $68.78 \%$, positive predictive value (PPV) $81.4 \%$ and negative predictive value (NPV) $70.3 \%$ (AUC $=0.795, \mathrm{Cl}: 0.691-0.898, \mathrm{p}<0.001$ ) and sensitivity of resistin $>0.27 \mathrm{ng} / \mathrm{mL}$ was $82.95 \%$ with a specificity of $59.12 \%$, PPV 75.2\% and NPV 65.24\% (AUC = 0.705, Cl:0.588-0.822, $\mathrm{p}<0.001$ ) for prediction for having the disease; EEC (Fig. 1). Besides both galanin and resistin levels were measured above cut off values in $37 \mathrm{EC}$ patients.

\begin{tabular}{|c|c|c|}
\hline Variables & OR $(95 \% \mathrm{Cl})$ & p \\
\hline BMI $\left[\mathrm{kg} / \mathrm{m}^{2}\right]$ & $0.931(0.802-1.079)$ & 0.335 \\
\hline Age [years] & $1.067(0.994-1.147)$ & 0.067 \\
\hline $\mathrm{FBG}[\mathrm{mg} / \mathrm{dL}]$ & $0.995(0.974-1.019)$ & 0.720 \\
\hline $\mathrm{FI}[\mu \mathrm{IU} / \mathrm{mL}]$ & $0.758(0.462-1.236)$ & 0.263 \\
\hline HOMA-IR & $3.847(0.632-23.314)$ & 0.145 \\
\hline TG [mg/dL] & $0.994(0.978-1.006)$ & 0.991 \\
\hline $\mathrm{HDL}[\mathrm{mg} / \mathrm{dL}]$ & $1.008(0.966-1.054)$ & 0.680 \\
\hline LDL [mg/dL] & $0.985(0.922-1.054)$ & 0.682 \\
\hline $\mathrm{TC}[\mathrm{mg} / \mathrm{dL}]$ & $1.018(0.968-1.073)$ & 0.472 \\
\hline Galanin >0.3716 [ng/mL] & $1.888(0.273-13.030)$ & 0.519 \\
\hline Resistin $>0.2757[\mathrm{ng} / \mathrm{mL}]$ & $1.048(0.163-6.767)$ & 0.961 \\
\hline $\begin{array}{l}\text { Galanin }>0.3716[\mathrm{ng} / \mathrm{mL}] \text { by } \\
\text { Resistin }>0.2757[\mathrm{ng} / \mathrm{mL}]\end{array}$ & $27.182(6.653-111.109)$ & $<0.001$ \\
\hline
\end{tabular}

$\mathrm{BMI}$ - body mass index; FBG — fasting blood glucose; $\mathrm{FI}$ - fasting insulin; HOMA-IR - Homeostasis Model Assessment-Insulin resistance; TC — total cholesterol; $\mathrm{HDL}$ - high density lipoprotein; LDL — low density lipoprotein TG - triglycerides; statistical significance $p<0.05$

Bivariate logistic regression analysis showed that, increased galanin concentration, greater than $0.37 \mathrm{ng} / \mathrm{mL}$, increased the risk of having EEC 10.2 times ( $95 \% \mathrm{Cl}$ : $3.425-$ $-30.881, \mathrm{p}<0.001$ ) and resistin concentration $>0.27 \mathrm{ng} / \mathrm{mL}$, increased the risk of having EEC 5.6-fold (95\% Cl: 1.939 $-16.282, p=0.001)$. On the other hand, according to adjusted Odds Ratio results of the multiple logistic regression analysis, effect of interaction between galanin and resistin on having EEC was statistically significant. Increased galanin concentration $>0.37 \mathrm{ng} / \mathrm{mL}$ with increased resistin concentration $>0.27 \mathrm{ng} / \mathrm{mL}$ had adjusted Odds Ratio $=27.182$ times greater risk of having EEC $(95 \% \mathrm{Cl}: 6.653$ to 111.109, p < 0.001) (Tab. 3)

\section{DISCUSSION}

In present study, age and BMI matched study and control group were included. Serum concentrations of resistin and galanin were found to be higher in patients with EEC. There have been no study investigating both galanin and resistin in this group of women. To the best of our knowledge, there have been only one study about increased GALR1 methylation in vaginal swabs of patients with EC [8]. Besides, only one study was observed determining increased resistin concentrations in patients with EC [15].

In present study, serum galanin concentrations were positively correlated with BMI.This is similar to some recent studies. Mainly in literature, it is known as galanin increases food intake and cause tendency to obesity in animals by 
way of GAL1 receptors. Only in limited number of studies, there was interestingly, no difference in plasma galanin concentration between obese and normal weight women [15].

Besides, in present study, it was determined that galanin was correlated with fasting insulin and HOMA-IR. In literature there have been conflicting results about galanin and insulin resistance. Bu L et al. determined that, in healthy and type 2 diabetic rats, to accelerate glucose uptake and to increase insulin sensitivity, endogenous galanin may enhance GLUT4 translocation, through its central receptor, [16]. Interestingly, in literature it is known that galanin suppress the release of insulin from the pancreatic islets. In dogs, it was determined that, in a dose-dependent manner synthetic galanin was found to inhibit basal insulin secretion. In vitro, glucose-stimulated insulin secretion from isolated rat pancreatic islets $B$ cells, was inhibited by galanin and its fragment galanin (1-15) NH2. So there seems to be the dual effect of endogenous galanin. One is to inhibit insulin secretion and the other is facilitating GLUT4 translocation and elevating insulin sensitivity and glucose intolerance [17].

In present study, serum galanin concentrations were not correlated with TG, TC, HDL and LDL levels. However in literature, it was reported that the galanin contents were positively correlated with elevated circulating triglyceride levels in rats and humans. There have been data supporting the hypothesis that galanin increases fat storage and induces obesity by increasing muscle to utilize carbohydrate more than fat [18]. Conflicting results may be due to optimal control of blood lipids by drugs, diets and routine exercise. Besides, in studies determining relationship between TG and galanin were performed mostly in animals with high fat diet rather than high carbohydrate.

In present study, majority of patients were obese. Resistin was not correlated with BMI. In literature, some studies showed that there might be a correlation between higher serum resistin levels and higher BMI and obesity [19] however contradictory studies have been published so far. For example, in patients with postmenopausal breast cancer, resistin was not correlated with BMI [20]. Similar to result of our study, Hlavna et al., stated that resistin levels were not correlated with BMI [15].

In our study, resistin levels were positively correlated with HOMA-IR and fasting insulin. However, again like correlation between $\mathrm{BMI}$ and resistin, association between insulin resistance and resistin has not been consistently observed in human clinical studies [21] and at time, the role of resistin in metabolic deregulations remained as controversial. Some authors indicated that increased serum resistin levels were associated with increased obesity, visceral fat [22] type 2 diabetes and metabolic syndrome [23] while other groups failed to observe such correlations [24]. In a study of 45 mixed cancer patients versus 25 healthy controls, resistin and its relation to weight loss, appetite and insulin resistance along with other adipokines was investigated. Resistin levels were similar between groups and did not correlate with body weight, body weight change, appetite and insulin resistance [25]. Conflicting results about resistin might be due to fact that, resistin was a marker of visceral obesity and due to that, might not be correlated with BMI of patients but correlated with fasting insulin and HOMA-IR.

In present study, we have determined that resistin was directly correlated with TG but not with HDL, LDL and TC levels. Correlated with, in literature, the studies investigating the role of resistin in dyslipidemia are highly contradictory. It is known that resistin seems to activate de novo hepatic lipogenesis and control peripheral lipid metabolism [26]. Some studies have found that plasma resistin levels were positively correlated with serum apolipoprotein B levels and triglycerides [27]. It was also found that it was inversely correlated with HDL cholesterol [28] and apolipoprotein A1 levels. It was determined that these associations were primarily in women. Whereas only TG levels were found to correlate with plasma resistin levels in men [29]. So gender may affect the relationship between lipid concentrations and resistin.

Among all participants, for galanin, it was also determined that correlation between BMI, fasting insulin and HOMA-IR was observed especially in patients younger than 60 years. That difference might be due to receptor sensitivity with age. Because, in literature, there have been researches about decreased Gal1R expression with age [30]. So, researches performed at different galanin receptor types are needed. For resistin, it was also determined that correlation between fasting insulin and HOMA-IR but not with $\mathrm{BMI}$, was observed especially in patients older than 60 . That might be probably due to the increase in the body visceral fat content with age.

In the present study, both galanin and resistin had predictive value for having EEC. Of course, it was important to differentiate if these markers were higher in EEC group and had predictive value due to interaction between these parameters and demographic and clinical properties of the patients or only the reason was having disease EC. First of all, age and BMI matched study and control group were included. Besides, in our study, mean age of control and EEC group was $<60$ years and in this population only galanin was correlated with BMI, fasting insulin and HOMA-IR but resistin was not correlated with these demographic parameters. This show us both increase in galanin and resistin increase risk of having EC but especially resistin increase may directly-not influenced by demographic parameters- increase risk of having EEC. This is same as study of Ozgor Yüksel B and et al. [31]. They, first time, had demonstrated that Resistin $420 \mathrm{G}>\mathrm{C}$ and $62 \mathrm{G}>\mathrm{A}$ gene polymorphisms play a role in EC development. 
In EEC group, it was determined that maternal galanin and resistin concentrations were not different in patients with more than half of myometrial invasion, grade and stage. Only galanin concentrations were lower in patients with lymph node positivity. In literature there have been different clinical studies about resistin and galanin concentrations in different cancer types. For galanin, it was shown that galanin receptor 2 (GALR2) re-expression can inhibit cell proliferation and induce apoptosis in head and neck squamous cell cancer (HNSCC) cells with mutant p53 [32]. The galanin expression level was significantly increased with tumor size and tumor stage in colon cancer. There have been also studies about triple therapy with octreotide, galanin and serotonin appears to improve the survival rate of the mice bearing human pancreatic carcinoma. Galanin has also been known to be involved in pathophysiology of neuroendocrine tumors and the carcinogenesis [7]. In another study performed in patients with cutaneous melanoma, galanin showed no relationship with any of the clinical and histological prognostic markers [33]. On the other hand, it was determined that resistin increases metastasis of chondrosarcoma [34] pancreatic cancer, gastric cancer [35]. In present knowledge, only one study for each marker in EC, but telling nothing about different stages of disease $[8,15]$.

However there are some limitations to our study. According to FIGO histopathologic staging system, 31 patients (59.6\%) were FIGO Stage 1A, 11 (21.3\%) patients were FIGO Stage $1 \mathrm{~B}, 4$ patients (7.6\%) were FIGO Stage 2, 3 patients 169 (6.4\%) were FIGO Stage 3A, 3 patients (6.4\%) were FIGO Stage $3 B$. The main limitation of the study is low number of patients with EC in advanced stages - therefore comparison of galanin and resistin between patients in different stages is unavailable.Besides we were not able to analyze the serum value of galanin and resistin of patients with ECC after treatment of cancer. It is because some patients in the study have been lost to follow up after treatment. Further studies are advised to analyze this. Patients complicated with precancerous lesions like atypical hyperplasia which is pre-cancer state were not within the scope of the current study. Subsequent studies should further analyze this issue. We think it is cost-effective to check the serum values of these markers. Performing serum value of both markers costs about 15 dollars. But our study was not a study to establish the cost-effectiveness of these markers. But it is advised to check the cost-effectivity in subsequent studies. In present study, we also did not study expression of galanin and resistin in tissue of ECC immunohistochemically due to financial cost. This is another limitation of our study. Further studies should analyze the expression of galanin and resistin in EEC cells or should analyze the expression or the concentration of galanin and resistin by human endometrial cell lines or culture solution.

\section{CONCLUSIONS}

In conclusion, increased galanin and resistin levels-especially resistin- either separately or together with seemed to increase the risk of EEC other than different risk factors including having DM, increased BMI and age etc, in our age and BMI matched groups study. Data of present study supported the fact that adiposity and inflammation, may have significant interaction effect in pathogenesis of EEC. However present study is a preliminary study, including small number of cases. So multicenter, may be genetic and molecular researches including high number of cases, with different stages of illness are needed to make a comparison and confirm results of our study.

\section{Conflict of interest}

All authors declare no conflict of interest. There was no involvement of a pharmaceutical or any other company.

\section{REFERENCES}

1. Banas T, Juszczyk G, Pitynski K, et al. Incidence and mortality rates in breast, corpus uteri, and ovarian cancers in Poland (1980-2013): an analysis of population-based data in relation to socioeconomic changes. Onco Targets Ther. 2016; 9: 5521-5530, doi: 10.2147/OTT.S112187, indexed in Pubmed: 27660470.

2. Zeimet AG, Reimer D, Huszar M, et al. L1CAM in early-stage type I endometrial cancer: results of a large multicenter evaluation. J Natl Cancer Inst. 2013; 105(15): 1142-1150, doi: 10.1093/jnci/djt144, indexed in Pubmed: 23781004.

3. Housa D, Vernerova Z, Heracek J, et al. Adipocytokines and cancer. Physiol Res. 2006; 55(3): 233-244, indexed in Pubmed: 16238454.

4. Joshi RK, Kim WJ, Lee SA. Association between obesity-related adipokines and colorectal cancer: a case-control study and meta-analysis. World J Gastroenterol. 2014; 20(24): 7941-7949, doi: 10.3748/wjg. v20.i24.7941, indexed in Pubmed: 24976730.

5. Fang PH, Yu M, Ma YP, et al. Central nervous system regulation of food intake and energy expenditure: role of galanin-mediated feeding behavior. Neurosci Bull. 2011;27(6): 407-412, doi: 10.1007/s12264-011-1841-7, indexed in Pubmed: 22108817.

6. Uehara T, Kanazawa T, Mizukami H, et al. Novel anti-tumor mechanism of galanin receptor type 2 in head and neck squamous cell carcinoma cells. Cancer Sci. 2014; 105(1): 72-80, doi: 10.1111/cas.12315, indexed in Pubmed: 24168112.

7. El-Salhy M, Tjomsland V, Theodorsson E. Effects of triple treatment with octreotide, galanin and serotonin on a human pancreas cancer cell line in xenografts. Histol Histopathol. 2005; 20: 745-752.

8. Doufekas $\mathrm{K}$, Hadwin R, Kandimalla R, et al. GALR1 methylation in vaginal swabs is highly accurate in identifying women with endometrial cancer. Int J Gynecol Cancer. 2013; 23(6): 1050-1055, doi: 10.1097/IGC.0b013e3182959103, indexed in Pubmed: 23727823.

9. Asgary S, SamsamShariat SZ, Ghorbani A, et al. Relationship between serum resistin concentrations with metabolic syndrome and its components in an Iranian population. Diabetes Metab Syndr. 2015; 9(4): 266-270, doi: 10.1016/j.dsx.2014.09.007, indexed in Pubmed: 25311818.

10. Aquilante $C L$, Kosmiski LA, Knutsen SD, et al. Relationship between plasma resistin concentrations, inflammatory chemokines, and components of the metabolic syndrome in adults. Metabolism. 2008; 57(4): 494-501, doi: 10.1016/j.metabol.2007.11.010, indexed in Pubmed: 18328350.

11. Dalamaga M. Obesity, insulin resistance, adipocytokines and breast cancer: New biomarkers and attractive therapeutic targets. World J Exp Med. 2013; 3(3): 34-42, doi: 10.5493/wjem.v3.i3.34, indexed in Pubmed: 24520544.

12. Radikova Z. Assessment of insulin sensitivity/resistance in epidemiological studies. Endocr Regul. 2003; 37(3): 189-194, indexed in Pubmed: 14986725.

13. Matthews DR, Hosker JP, Rudenski AS, et al. Homeostasis model assessment: insulin resistance and beta-cell function from fasting plasma 
glucose and insulin concentrations in man. Diabetologia. 1985; 28(7): 412-419, doi: 10.1007/BF00280883, indexed in Pubmed: 3899825.

14. Creasman W. Revised FIGO staging for carcinoma of the endometrium. Int J Gynaecol Obstet. 2009; 105(2): 109, doi: 10.1016/j.ijgo.2009.02.010, indexed in Pubmed: 19345353.

15. Hlavna M, Kohut L, Lipkova J, et al. Relationship of resistin levels with endometrial cancer risk. Neoplasma. 2011; 58(2): 124-128, doi: 10.4149/neo_2011_02 124, indexed in Pubmed: 21275461.

16. Bu Le, Liu Z, Zou J, et al. Blocking central galanin receptors attenuates insulin sensitivity in myocytes of diabetic trained rats. J Neurosc Res. 2013; 91(7): 971-977, doi: 10.1002/jnr.23228, indexed in Pubmed: 23653288.

17. Manabe T, Okada Y, Sawai H, et al. Effect of galanin on plasma glucose, insulin and pancreatic glucagon in dogs. J Int Med Res. 2003; 31(2): 126-132, doi: 10.1177/147323000303100209, indexed in Pubmed: 12760316.

18. Fang P, Yu M, Guo L, et al. Galanin and its receptors: a novel strategy for appetite control and obesity therapy. Peptides. 2012; 36(2): 331-339, doi: 10.1016/j.peptides.2012.05.016, indexed in Pubmed: 22664322.

19. Azuma K, Katsukawa F, Oguchi $S$, et al. Correlation between serum resistin level and adiposity in obese individuals. Obes Res. 2003; 11(8): 997-1001, doi: 10.1038/oby.2003.137, indexed in Pubmed: 12917505.

20. Dalamaga M, Sotiropoulos G, Karmaniolas K, et al. Serum resistin: a biomarker of breast cancer in postmenopausal women? Association with clinicopathological characteristics, tumor markers, inflammatory and metabolic parameters. Clin Biochem. 2013; 46(7-8): 584-590, doi: 10.1016/j.clinbiochem.2013.01.001, indexed in Pubmed: 23321342.

21. Chen CC, Li TC, Li Cl, et al. Serum resistin level among healthy subjects: relationship to anthropometric and metabolic parameters. Metabolism. 2005; 54(4): 471-475, doi: 10.1016/j.metabol.2004.10.015, indexed in Pubmed: 15798953.

22. Matsuda M, Kawasaki F, Yamada K, et al. Impact of adiposity and plasma adipocytokines on diabetic angiopathies in Japanese Type 2 diabetic subjects. Diabet Med. 2004; 21(8): 881-888, doi: 10.1111/j.1464-5491. 2004.01261.x, indexed in Pubmed: 15270792.

23. Bauer $S$, Neumeier M, Wanninger J, et al. Systemic resistin is increased in type 2 diabetic patients treated with loop diuretics. J Diabetes Complications. 2011; 25(6): 377-381, doi: 10.1016/j.jdiacomp.2011.06.001, indexed in Pubmed: 21813294.

24. Utzschneider KM, Carr DB, Tong J, et al. Resistin is not associated with insulin sensitivity or the metabolic syndrome in humans. Diabetologia.
2005; 48(11): 2330-2333, doi: 10.1007/s00125-005-1932-y, indexed in Pubmed: 16143861.

25. Ntikoudi E, Kiagia M, Boura P, et al. Hormones of adipose tissue and their biologic role in lung cancer. Cancer Treat Rev. 2014; 40(1): 22-30, doi: 10.1016/j.ctrv.2013.06.005, indexed in Pubmed: 23870486.

26. Abate N, Sallam HS, Rizzo M, et al. Resistin: an inflammatory cytokine. Role in cardiovascular diseases, diabetes and the metabolic syndrome. Curr Pharm Des. 2014; 20(31): 4961-4969, doi: 10.2174/138161281966 6131206103102, indexed in Pubmed: 24320036.

27. Singh AK, Tiwari S, Gupta A, et al. Association of resistin with metabolic syndrome in Indian subjects. Metab Syndr Relat Disord. 2012; 10(4): 286-291, doi: 10.1089/met.2011.0128, indexed in Pubmed: 22506726.

28. Oh KiW, Lee WY, Rhee EJ, et al. The relationship between serum resistin, leptin, adiponectin, ghrelin levels and bone mineral density in middle-aged men. Clin Endocrinol (Oxf). 2005; 63(2): 131-138, doi: 10.1111/j.1365-2265.2005.02312.x, indexed in Pubmed: 16060905.

29. Norata GD, Ongari M, Garlaschelli K, et al. Plasma resistin levels correlate with determinants of the metabolic syndrome. Eur J Endocrinol. 2007; 156(2): 279-284, doi: 10.1530/eje.1.02338, indexed in Pubmed: 17287419.

30. Matkowskyj K, Royan SV, Blunier A, et al. Age-dependent differences in galanin-dependent colonic fluid secretion after infection with Salmonella typhimurium. Gut. 2009; 58(9): 1201-1206, doi: 10.1136/gut.2008.163832, indexed in Pubmed: 19671554.

31. Ozgor BY, lyibozkurt C, Bastu E, et al. Investigation of resistin 420 and 62 gene polymorphism in patients with endometrial cancer. Taiwan J Obstet Gynecol. 2019; 58(1): 164-167, doi: 10.1016/j.tjog.2018.11.030, indexed in Pubmed: 30638473.

32. Kanazawa T, Kommareddi PK, Iwashita T, et al. Galanin receptor subtype 2 suppresses cell proliferation and induces apoptosis in p53 mutant head and neck cancer cells. Clin Cancer Res. 2009; 15(7): 2222-2230, doi: 10.1158/1078-0432.CCR-08-2443, indexed in Pubmed: 19276245.

33. Gilaberte Y, Vera J, Coscojuela C, et al. Expression of Galanin in Melanocytic Tumors. Actas Dermo-Sifiliográficas (English Edition). 2007; 98(1): 24-34, doi: 10.1016/s1578-2190(07)70386-4.

34. Tsai $\mathrm{CH}$, Tsai HC, Huang HN, et al. Resistin promotes tumor metastasis by down-regulation of miR-519d through the AMPK/p38 signaling pathway in human chondrosarcoma cells. Oncotarget. 2015; 6(1): 258-270, doi: 10.18632/oncotarget.2724, indexed in Pubmed: 25404641.

35. Wallace AE, Gibson DA, Saunders PTK, et al. Inflammatory events in endometrial adenocarcinoma. J Endocrinol. 2010; 206(2): 141-157, doi: 10.1677/JOE-10-0072, indexed in Pubmed: 20406782. 